UCRL-JC- 128388

PREPRINT

\title{
Thermodynamics of Insulated Pressure Vessels for Vehicular Hydrogen Storage
}

\author{
Salvador M. Aceves and Gene D. Berry
}

This paper was prepared for submittal to International Mechanical Engineering Congress and Exposition

Dallas, Texas

November 16-21, 1997

June 30, 1997

This is a preprint of a paper intended for publication in a journal or proceedings. Since changes may be made before publication, this preprint is made available with the understanding that it will not be cited or reproduced without the permission of the author. 


\title{
THERMODYNAMICS OF INSULATED PRESSURE VESSELS * FOR VEHICULAR HYDROGEN STORAGE
}

\author{
Salvador M. Aceves and Gene D. Berry
}

\begin{abstract}
This paper studies the application of insulated pressure vessels for hydrogen-fueled light-duty vehicles. Insulated pressure vessels can store liquid hydrogen $\left(\mathrm{LH}_{2}\right)$; low-temperature $(80 \mathrm{~K})$ compressed hydrogen $\left(\mathrm{CH}_{2}\right)$; or ambienttemperature $\mathrm{CH}_{2}$. In this analysis, hydrogen temperatures, pressures and venting losses are calculated for insulated pressure vessels fueled with $\mathrm{LH}_{2}$ or with low-temperature $\mathrm{CH}_{2}$, and the results are compared to those obtained in low-pressure $\mathrm{LH}_{2}$ tanks. Hydrogen losses are calculated as a function of daily driving distance during normal operation; as a function of time during long periods of vehicle inactivity; and as a function of initial vessel temperature during fueling. The number of days before any venting losses occur is also calculated as a function of the daily driving distance.
\end{abstract}

The results show that insulated pressure vessels have packaging characteristics comparable to those of conventional, low-pressure $\mathrm{LH}_{2}$ tanks (low weight and volume), with greatly improved dormancy and much lower boil-off. Insulated pressure vessels used in a $17 \mathrm{~km} / 1(40 \mathrm{mpg})$ car do not lose any hydrogen when the car is driven at least $15 \mathrm{~km} /$ day in average. Since almost all cars are driven for longer distances, most cars would never lose any hydrogen. Losses during long periods of parking are also relatively small. Due to their high-pressure capacity, these vessels would retain about a third of their full charge even after a very long dormancy, so that the owner would not risk running out of fuel. If an insulated pressure vessel reaches ambient temperature, it can be cooled down very effectively by fueling it with $\mathrm{LH}_{2}$ with no losses during fueling. The vessel has good thermal performance even when thermally insulated with inexpensive microsphere insulation. In addition, the insulated pressure vessels greatly ease fuel availability and infrastructure requirements, since it would be compatible with both compressed and cryogenic hydrogen refueling.

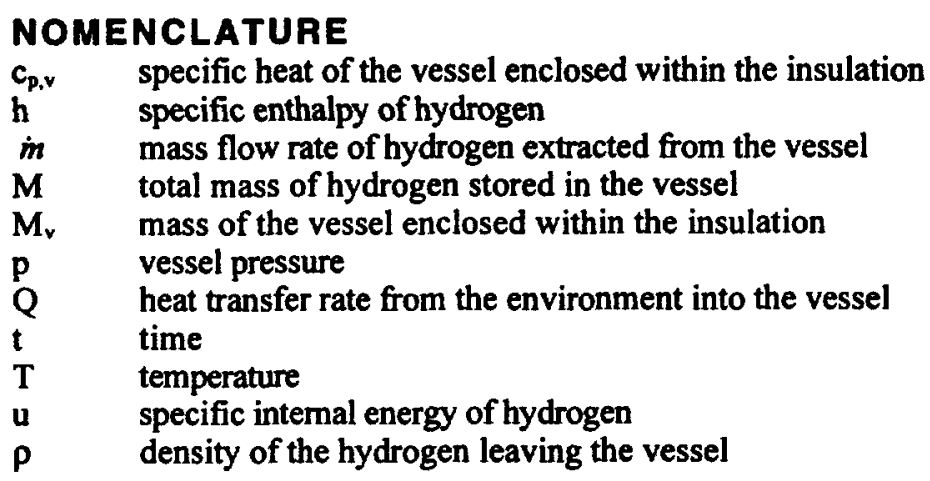

\section{INTRODUCTION}

In the search for an alternative to today's petroleum-powered vehicles, efficient hydrogen-fueled vehicles are an attractive solution. Hydrogen vehicles can use the advanced technology of electric vehicles to improve environmental quality and energy security, while providing the range, performance and utility of today's gasoline vehicles. 
Probably the most significant hurdle for hydrogen vehicles is storing sufficient hydrogen onboard. Hydrogen storage choices can determine the refueling time, cost, and infrastructure requirements, as well as indirectly influence energy efficiency, vehicle fuel economy, performance, and utility. There are at least three viable technologies for storing hydrogen fuel on cars. These are: compressed hydrogen gas $\left(\mathrm{CH}_{2}\right)$, metal hydride adsorption, and cryogenic liquid hydrogen $\left(\mathrm{LH}_{2}\right)$, but each has significant disadvantages.

Storage of $5 \mathrm{~kg}$ of hydrogen (equivalent to 19 liters; 5 gallons of gasoline) is considered necessary for a generalpurpose vehicle, since it provides a $320 \mathrm{~km}(200$ mile) range in a $17 \mathrm{~km} /$ liter $(40 \mathrm{mpg})$ conventional car; or a 640 $\mathrm{km}$ (400 mile) range in a $34 \mathrm{~km} /$ iter $(80 \mathrm{mpg})$ series hybrid vehicle or fuel cell vehicle. Storing this hydrogen as $\mathrm{CH}_{2}$ requires a volume so big that it probably cannot be used in light-duty vehicles, and it certainly cannot be used in trucks. The volume for a pressurized vessel storing $5 \mathrm{~kg}$ of hydrogen at $24.8 \mathrm{MPa}$ (3600 psi) is 320 liters (85 gal). Hydrides are heavy ( $300 \mathrm{~kg}$ for $5 \mathrm{~kg}$ of hydrogen, Michel et al., 1996), resulting in a substantial reduction in vehicle fuel economy and performance.

Low-pressure $\mathrm{LH}_{2}$ storage is light and compact, and has received significant attention due to its advantages for packaging (Braess and Strobl, 1996). Significant recent developments have resulted in improved safety (Pehr, 1996a) and fueling infrastructure (Hettinger et al., 1996). Disadvantages of low-pressure $\mathrm{LH}_{2}$ storage are:

1. The substantial amount of electricity required for liquefying the hydrogen (at least $30 \%$ of the lower heating value of hydrogen, as indicated by Peschka, 1992).

2. The evaporation losses that occur during fueling low-pressure $\mathrm{LH}_{2}$ tanks. These are the result of using the hydrogen to cool down the connecting hoses, and have recently been reported as $8 \%$ of the total hydrogen pumped into the vessel (Wetzel, 1996).

3. The evaporation losses that occur during long periods of dormancy, due to heat transfer from the environment. Hydrogen losses reduce the range of the vehicle and the effective fuel economy (distance traveled divided by the amount of fuel deposited into the vessel). They may also represent a safety hazard, and a great inconvenience for a driver that may find the vehicle with very little fuel after a long period of dormancy (e.g. 2 weeks).

An alternative is to store hydrogen in an insulated pressure vessel that has the capacity to operate at low temperature (as low as $20 \mathrm{~K}$ ), and high pressure (up to $24.8 \mathrm{MPa} ; 3600 \mathrm{psi}$ ). This vessel can store either $\mathrm{LH}_{2}$, or $\mathrm{CH}_{2}$ at $80 \mathrm{~K}$ and $24.8 \mathrm{MPa}$. $\mathrm{CH}_{2}$ at $80 \mathrm{~K}$ and $24.8 \mathrm{MPa}$ is nearly as dense as $\mathrm{LH}_{2}$, and therefore can be used in light-duty conventional or hybrid vehicles to obtain a long range without excessive weight or volume. The vessel can also be fueled with $\mathrm{CH}_{2}$ at ambient temperature if this is desired, or if cryogenic hydrogen is not available due to limitations in the hydrogen infrastructure. Filling the vessel with ambient-temperature $\mathrm{CH}_{2}$ reduces the amount of hydrogen stored (and therefore the vehicle range) to about a third of its value with $\mathrm{LH}_{2}$ or $80 \mathrm{~K} \mathrm{CH}_{2}$ storage.

These facts speak favorably of onboard hydrogen storage in an insulated pressure vessel, but there are a number of caveats. First, cryogenic storage requires more energy and technical sophistication in the fuel delivery infrastructure than ambient storage methods. Second, cryogenic storage systems may eventually warm up, potentially requiring the release of hydrogen to relieve pressure build-up.

These caveats actually enhance the case for an insulated pressure vessel over low-pressure $\mathrm{LH}_{2}$ storage, because a car with an insulated pressure vessel can use, but does not require, cryogenic hydrogen fuel. A series hybrid or fuel cell vehicle $\left(34 \mathrm{~km} / 1,80 \mathrm{mpg}\right.$ ) could be refueled with ambient-temperature $\mathrm{CH}_{2}$ at $24.8 \mathrm{MPa}(3600 \mathrm{psi})$ and still achieve a $200 \mathrm{~km}$ range, suitable for the majority of trips. The additional energy, costs, and technological effort for cryogenic refueling need only be undertaken (and paid for) when the additional range is desired for longer trips. With an insulated pressure vessel, vehicles can refuel most of the time with ambient-temperature hydrogen, using less energy, and most likely at lower ultimate cost than $\mathrm{LH}_{2}$ or low-temperature $\mathrm{CH}_{2}$, but with the capability of having 3 times the range of room temperature storage systems. In addition, if the vessel warms up to ambient temperature after a long period of dormancy, the vehicle still has about a third of its original range.

From an engineering and economic perspective, insulated pressure vessels strike a versatile balance between the cost and bulk of room temperature $\mathrm{CH}_{2}$ storage, and the energy efficiency, thermal insulation and dormancy issues of $\mathrm{LH}_{2}$ vehicular storage. 
This paper presents a thermodynamic analysis of hydrogen venting losses from insulated pressure vessels during vehicle operation, vehicle dormancy, and vessel fueling. A conventional, low-pressure $(0.5 \mathrm{MPa}) \mathrm{LH}_{2} \operatorname{tank}$ is compared with insulated pressure vessels storing either $\mathrm{LH}_{2}$ or $\mathrm{CH}_{2}$ at $80 \mathrm{~K}, 24.8 \mathrm{MPa}$. Different insulation levels for the insulated pressure vessels are also considered. The following sections present the thermodynamic model used in the analysis and the characteristics of the vessels being compared.

\section{THERMODYNAMIC ANALYSIS}

This section describes a thermodynamic model of a pressure vessel. The following assumptions are used in the analysis:

1. Kinetic and potential energy of the hydrogen flowing out of the vessel are neglected.

2. Thermal conductivity of the vessel insulation is considered to be independent of internal and external temperature.

3. Gaseous hydrogen is preferentially extracted from the vessels. $\mathrm{LH}_{2}$ is only extracted when the amount of gaseous hydrogen is not enough to satisfy the driving requirements.

4. Temperature and pressure are uniform within the vessel. This assumption has recently been verified for small vessels of the size required for light-duty vehicles (Bunger and Owren, 1996).

5. No conversion between the para and ortho phases of hydrogen is considered. This assumption is used because vessel temperature changes little during most operating conditions, so that the equilibrium concentration of each phase remains fairly constant. In addition to this, the para-ortho conversion is slow, with a transition time of the order of a few days (Mathis, 1976), so that in most cases, hydrogen does not stay in the vehicle vessel long enough for any significant conversion to occur. For cases in which substantial temperature changes combine with long residence times, the effect of para-ortho conversion may be significant. In these cases, this assumption is expected to yield conservative results. This is because vehicles are likely to be fueled with hydrogen in phase equilibrium, which, for cryogenic hydrogen, has a high concentration of para-hydrogen. Considering that the conversion from para-hydrogen to ortho-hydrogen is endothermic, hydrogen conversion from para to ortho tends to keep the vessel cold, reducing hydrogen losses from the vessel.

The first law of thermodynamics written for a pressure vessel is (Van Wylen and Sonntag, 1978):

$$
\frac{d(M u)}{d t}+M_{v} \frac{d\left(c_{p, v} T\right)}{d t}=Q-h \dot{m}
$$

In this equation, $M$ is the total mass of hydrogen stored in the vessel, $u$ is the specific internal energy of the hydrogen, $t$ is time, $M_{v}$ and $c_{p, v}$ are the mass and specific heat of the vessel within the insulation, $T$ is vessel temperature, $\mathrm{h}$ is the specific enthalpy of the gaseous hydrogen, $m$ is the mass flow rate of hydrogen extracted from the vessel, and $Q$ is heat transfer rate from the environment into the vessel. Use of the identities $h \equiv u+p / p$ and $m \equiv$ $-\mathrm{dM} / \mathrm{dt}$, reduces Equation (1) to:

$$
M \frac{d u}{d t}+M_{v} \frac{d\left(c_{p, v} T\right)}{d t}=Q-\left(\frac{p}{\rho}\right) \dot{m}
$$

where $p$ is the vessel pressure, and $p$ is the density of the hydrogen leaving the vessel. The left-hand side in Equation (2) is positive when the temperature increases as a function of time, and negative when the temperature decreases. The right-hand side determines the rate of change in the temperature of the vessel. Heat transfer into the vessel ( $Q$ in the equation) is positive and; as expected, tends to increase the temperature of the vessel. However, mass flow out of the vessel has a negative contribution to the change in temperature in the vessel. Considering that the density of hydrogen is very low, this term reduces the heating effect of $Q$, and it may even result in a reduction in temperature for the vessel, depending on the rate of mass extraction $\dot{m}$. The last term in Equation (2) is commonly known as the flow work, since it is the work that the hydrogen stored in the vessel has to do to push out the hydrogen being extracted. 
Equation (2) also applies to the process of filling the vessel. In this case, $\dot{m}$ is negative and the flow work tends to increase the temperature of the hydrogen stored in the vessel. While this effect is negligible for $\mathrm{LH}_{2}$, for $\mathrm{CH}_{2}$ results in important increases in temperature. Storing $\mathrm{CH}_{2}$ at $80 \mathrm{~K}$ inside the vessel requires $\mathrm{CH}_{2}$ to be stored at 46 $\mathrm{K}$ in the fueling station. Fueling with $300 \mathrm{~K} \mathrm{CH}_{2}$ results in a final $\mathrm{CH}_{2}$ temperature of $433 \mathrm{~K}$. It may be necessary to fuel the vessel with cold $(210 \mathrm{~K}) \mathrm{CH}_{2}$ to achieve a full load at $300 \mathrm{~K}$.

Equation (2) is solved for a low-pressure $\mathrm{LH}_{2}$ storage and for the insulated pressure vessel. The equation is solved iteratively with a computer program which includes subroutines for calculating hydrogen properties. The required property values are obtained from McCarty (1975). The problem that appears more frequently in the analysis is finding pressure and temperature when internal energy and density are known. The specific heat of the vessel materials, $c_{p, v}$ is obtained as a function of temperature from correlations given in the literature (Scott, 1967). For vessels made of two materials (i.e., carbon fiber and aluminum), the second term in the left-hand side of Equation (2) is written as a sum of two terms, each taking into account the thermal mass of each material.

\section{VESSEL CHARACTERISTICS}

This paper considers five vessels, described as follows:

1. A conventional, low-pressure $\mathrm{LH}_{2}$ tank with a multilayer vacuum superinsulation (MLVSD) and $0.5 \mathrm{MPa}$ maximum operating pressure.

2. An insulated pressure vessel (24.8 MPa maximum operating pressure) with MLVSI fueled with $\mathrm{LH}_{2}$.

3. An insulated pressure vessel with microsphere insulation (aluminized microspheres within a vacuum) fueled with $\mathrm{LH}_{2}$.

4. An insulated pressure vessel with MLVSI storing $\mathrm{CH}_{2}$ at $80 \mathrm{~K}$ and $24.8 \mathrm{Mpa}$ (fueled with $\mathrm{CH}_{2}$ at $46 \mathrm{~K}$ ).

5. An insulated pressure vessel with microsphere insulation storing $\mathrm{CH}_{2}$ at $80 \mathrm{~K}$ and $24.8 \mathrm{MPa}$.

Vessel properties are listed in Table 1. Vessels 2 and 4 are identical except for the state of the hydrogen fuel provided to the vessel, and the same is true for Vessels 3 and 5 . Therefore, only three vessel descriptions are necessary.

All vessels are designed to store $5 \mathrm{~kg}$ of hydrogen. Total weight is calculated from the value of the pressure vessel performance factor, defined as burst pressure multiplied by internal volume, and divided by weight. The weight of accessories, insulation, and external cover are calculated from data given by James et al. (1996). Both MLVSI and microspheres are light compared to other vessel components, resulting in approximately equal weight for Vessels 2 through 5 . The vessels are assumed to have a cylindrical shape with hemispherical ends, and the length of the cylindrical segment is assumed to be equal to the diameter. The mass of aluminum and carbon enclosed within the insulation is estimated from the data given by James et al. (1996). Insulation properties are obtained from Bunger and Owren (1996), who list ranges of measured conductivity. Worst-case (highest) conductivity values are selected from these ranges.

The heat transfer rate, $Q$, has two components: heat transfer through the insulation, and parasitic heat transfer. Heat transfer through the insulation is assumed proportional to the temperature difference between the environment and the hydrogen inside the vessel. The greatest heat transfer resistance is the vessel insulation, and the effect of other thermal resistances (convection inside and outside the vessel, conduction through the structural fibers of the vessels, etc.) is neglected. Parasitic heat transfer takes into account heat transfer through accessories, connecting lines, etc., and is assumed constant and equal to $0.5 \mathrm{~W}$.

The low-pressure $\mathrm{LH}_{2}$ storage tank is designed for a $0.5 \mathrm{MPa}$ maximum pressure, and it is fueled with $\mathrm{LH}_{2}$ at $20 \mathrm{~K}$. The insulated pressure vessel is designed for a $24.8 \mathrm{MPa}(3600 \mathrm{psi})$ maximum pressure. The insulated pressure vessel is either fueled with $20 \mathrm{~K} \mathrm{LH}_{2}$ or with $46 \mathrm{~K}, 24.8 \mathrm{MPa} \mathrm{CH}$. As previously established, fueling with $46 \mathrm{~K} \mathrm{CH}_{2}$ results in an $80 \mathrm{~K} \mathrm{CH}_{2}$ temperature inside the vessel. Two insulating materials (MLVSI and microspheres) are used in the analysis to study the effect of insulation level on hydrogen losses. No low-pressure $\mathrm{LH}_{2}$ tank with microsphere insulation is studied in this paper, because low-pressure $\mathrm{LH}_{2}$ tanks are very sensitive to 
heat transfer from the environment. According to Bunger and Owren (1996), $\mathrm{LH}_{2}$ poses requirements that are beyond the thermal performance of current vacuum powder insulation.

Table 1. Characteristics of the hydrogen vessels being analyzed. Vessels 2 and 4 are identical except for the state of the hydrogen fuel provided to the vessel, and the same is true for Vessels 3 and 5 .

Mass of hydrogen stored, $\mathbf{k g}$

Total weight, $\mathbf{k g}$

Internal vol., liters

External vol., liters

Internal diam., $m$

Internal surface area, $\mathrm{m}^{2}$

Mass contained within insulation, $\mathbf{~ k g}$

Aluminum mass within insulation, $\mathrm{kg}$

Carbon mass within insulation, $\mathrm{kg}$

Design pressure, MPa (psi)

Performance factor', $m$ ( $10^{6}$ in)

Safety factor

Insulating material

Thermal conductivity of insulator, $\mathrm{W} / \mathrm{mK}$

Insulation thickness, $\mathrm{m}$

Heat transfer through accessories, $W$

Ambient temp., $\mathrm{K}$

\begin{tabular}{ccc} 
liquid & \multicolumn{2}{c}{ insulated pressure vessels } \\
Tank 1 & Ves. 2 \& 4 & Ves. 3 \& 5 \\
5 & 5 & 5 \\
21 & 30 & 30 \\
85 & 95 & 95 \\
112 & 144 & 144 \\
0.39 & 0.42 & 0.42 \\
0.98 & 1.1 & 1.1 \\
9 & 20 & 20 \\
9 & 10 & 10 \\
0 & 10 & 10 \\
$0.5(70)$ & $24.8(3600)$ & $24.8(3600)$ \\
- & $33000(1.3)$ & $33000(1.3)$ \\
- & 2.25 & 2.25 \\
MLVSI $^{2}$ & MLVSI & micro-sphere \\
0.0001 & 0.0001 & 0.0004 \\
0.02 & 0.02 & 0.02 \\
0.5 & 0.5 & 0.5 \\
300 & 300 & 300
\end{tabular}

defined as burst pressure*volume/weight.

${ }^{2}$ MLVSI = multilayer vacuum superinsulation

This paper considers the application of hydrogen vessels to two vehicles: a conventional hydrogen vehicle with a $17 \mathrm{~km} /$ liter (40 mpg) gasoline-equivalent fuel economy (Aceves and Smith, 1996); and a high efficiency series hybrid or fuel cell car with a $34 \mathrm{~km} / \mathrm{l}(80 \mathrm{mpg}$ ) gasoline equivalent fuel economy (Smith et al., 1995). It is expected that the fuel economy of future hydrogen cars will fall somewhere in between these two values. The results of this paper can be easily scaled for application to vehicles with any other fuel economy.

\section{RESULTS}

This analysis considers four aspects of hydrogen storage vessel performance. These are: temperature and pressure inside the vessels; hydrogen losses during operation; hydrogen losses during a long dormancy; and hydrogen losses while fueling. Unless otherwise noted, the analysis assumes that the vessel starts with a full load of hydrogen, with a specified initial temperature.

Figures 1,2, and 3 show temperature and pressure inside the hydrogen vessels as a function of the day of operation since the vessel was filled, for three different daily driving distances, for a vehicle with a $17 \mathrm{~km} / \mathrm{liter}$ (40 $\mathrm{mpg}$ ) fuel economy. The figures can be used for vehicles with $34 \mathrm{~km} / \mathrm{liter}(80 \mathrm{mpg})$ fuel economy if the driving distances are multiplied by 2 (i.e., the $10 \mathrm{~km} /$ day curves in the figures correspond to $20 \mathrm{~km} /$ day for a vehicle with a $34 \mathrm{~km} /$ liter fuel economy). The results presented in this section are insensitive to the conditions under which the daily driving distance is driven. Little difference is obtained if the distance is covered in a single trip, over a number of short trips, or in a long, slow trip.

Figure 1 shows hydrogen temperature and pressure inside a low-pressure $\mathrm{LH}_{2}$ tank. The figure shows that both temperature and pressure increase rapidly until the pressure reaches the maximum operating pressure $(0.5 \mathrm{MPa})$. At this moment, the vessel starts venting hydrogen. The temperature remains at the saturation temperature corresponding to $0.5 \mathrm{MPa}(27.1 \mathrm{~K})$ until all the hydrogen inside the vessel evaporates. When all the hydrogen evaporates, the thermal capacity of the vessel and the remaining hydrogen is very low, resulting in a sudden increase in temperature. Figure 1 also shows an important characteristic of low-pressure $\mathrm{LH}_{2}$ tanks: temperature and pressure 
inside the vessel are a very weak function of daily driving distance. The reason is that the flow work (see Equation 2 ) is very small due to the low temperature and high density at which hydrogen is extracted from the vessel. Therefore, little cooling occurs as a result of extracting hydrogen from the vessel.

Figure 2 shows temperature and pressure inside an insulated pressure vessel with MLVSI fueled with $20 \mathrm{~K} \mathrm{LH}_{2}$. Temperatures and pressures increase as a function of time. The pressure does not reach the maximum operating pressure $(24.8 \mathrm{MPa})$, and therefore no hydrogen has to be vented within the time of operation shown in the figure. The figure shows that temperature and pressure are more sensitive to daily driving distance than in low-pressure $\mathrm{LH}_{2}$ tanks (Figure 1). The curves for different daily driving distances remain close to each other until the temperature increases enough for the flow work to become significant. At this point, the temperature and pressure curves for different driving distances separate rapidly. Figure 2 also shows that high pressures never occur simultaneously with very low temperatures inside the vessel, since the pressure only increases when the temperature increases. This may be important for the manufacture of these vessels. The vessels have to be designed for low temperature and high pressure, but the most extreme temperature and pressure conditions do not occur simultaneously. The sudden temperature increase in the vessel before the fuel runs out is again due to the diminished thermal capacity of the vessel and hydrogen.

Figure 3 shows temperature and pressure inside an insulated pressure vessel with MLVSI fueled with $46 \mathrm{~K} \mathrm{CH}_{2}$ ( $80 \mathrm{~K}$ initial fuel temperature inside the vessel). The figure shows that temperature and pressure are a strong function of daily driving distance. For the lowest driving distance $(3 \mathrm{~km} /$ day), the pressure rapidly reaches the maximum operating pressure. At this point, the vessel starts venting fuel. For $10 \mathrm{~km} /$ day, the pressure inside the vessel drops continuously, even as the temperature increases slowly. For a vehicle driven $30 \mathrm{~km} /$ day, the flow work is enough to reduce the temperature of the vessel during the period of operation, so that the temperature when the vessel runs out of fuel is lower than the initial vessel temperature.

Hydrogen losses during operation are shown in Figures 4 and 5. Figure 4 shows cumulative hydrogen losses in $\mathrm{kg}$ as a function of daily driving distance, for the five vessels being analyzed in this paper, starting with a full tank (5 $\mathrm{kg}$ ). The figure includes information for $17 \mathrm{~km} / 1$ and $34 \mathrm{~km} / 1$ cars respectively in the lower and upper $\mathrm{x}$-axes. The figure shows that a low-pressure $\mathrm{LH}_{2}$ tank loses hydrogen even when driven $50 \mathrm{~km}$ per day in a $17 \mathrm{~km} / \mathrm{lar}(100 \mathrm{~km}$ in a $34 \mathrm{~km} / \mathrm{lcar}$ ). Losses from a low-pressure $\mathrm{LH}_{2}$ tank grow rapidly as the daily driving distance drops. Insulated pressure vessels lose hydrogen only for very short daily driving distances. Even the worst case of a microsphereinsulated vessel storing $80 \mathrm{~K} \mathrm{CH}_{2}$ (Vessel 5) does not lose any hydrogen when driven $15 \mathrm{~km} /$ day or more (30 $\mathrm{km} /$ day in the $34 \mathrm{~km} / \mathrm{l}$ car). Since most people drive considerably more than this distance, no losses are expected under normal operating conditions, even for this worst case. Losses during operation from insulated pressure vessels are not very sensitive to the type of insulation and the initial state of the fuel. The low-pressure $\mathrm{LH}_{2} \operatorname{tank}$ loses almost all its hydrogen when the daily driving distance is reduced to zero. Insulated pressure vessels, on the other hand, keep about a third of their original hydrogen load, due to their high pressure capacity.

Figure 5 shows the number of days that the vehicle can operate with a full vessel of hydrogen (time before running out of fuel) as a function of daily driving distance. The results in this figure for the insulated pressure vessels are insensitive to initial fuel temperature, and therefore no results are shown for these vessels storing $80 \mathrm{~K} \mathrm{CH}_{2}$. These fall almost on top of the results given for fueling with $\mathrm{LH}_{2}$. A vessel with no losses is represented in Figure 5 by a hyperbola. This hyperbola coincides with the curve for the MLVSI insulated pressure vessel, because this vessel does not lose any hydrogen for the range of daily driving distance shown in the figure. The curve for the lowpressure $\mathrm{LH}_{2}$ tank is closer to a straight line than to a hyperbola. This is because hydrogen losses increase substantially as the daily driving distance is reduced. The figure indicates that a low-pressure $\mathrm{LH}_{2}$ tank has to be refueled at least every 16 days, regardless of how much the car is driven. Insulated pressure vessels do not have a minimum frequency for refueling, and lose very little or no hydrogen even when driving conditions are such that the vessel requires a refueling only every two months.

Figure 5 also indicates that hydrogen residence time in insulated pressure vessels may be substantially longer than for low-pressure $\mathrm{LH}_{2}$ tanks. Considering that conversion from para-hydrogen to ortho-hydrogen is slow, it is likely that significantly

more conversion may occur in insulated pressure vessels as compared with low-pressure $\mathrm{LH}_{2}$ tanks. Conversion from para-hydrogen to ortho-hydrogen is not considered in this analysis. However, it can be seen that this conversion may contribute to increasing the advantages of insulated pressure vessels, since, as previously stated, this conversion is endothermic, and would tend to reduce vessel losses. 
Figures 6 and 7 illustrate dormancy losses. Figure 6 shows cumulative hydrogen losses as a function of the number of days that the vehicle remains idle. The most unfavorable condition is assumed: the vehicles are parked immediately after fueling. The low-pressure $\mathrm{LH}_{2}$ tank is assumed to be initially at $20 \mathrm{~K}, 0.1 \mathrm{MPa}$. These initial conditions result in a period of 2 days before any hydrogen has to be vented. On the other hand, insulated pressure vessels with $80 \mathrm{~K} \mathrm{CH}_{2}$ start losing fuel in the first day, since they are originally filled to nearly their maximum pressure. However, insulated pressure vessels lose hydrogen slowly. After 6 days, the low-pressure $\mathrm{LH}_{2}$ storage loses more hydrogen than any of the insulated pressure vessels. Losses from the low-pressure $\mathrm{LH}_{2}$ storage increase quickly, and practically all of the hydrogen is lost after 15 days. Fueling the insulated pressure vessels with $\mathrm{LH}_{2}$ delays hydrogen losses, since no hydrogen is lost until it all evaporates and its pressure rises to $24.8 \mathrm{MPa}$. This delay is 5 days for the microsphere vessel, and 16 days for the MLVSI vessel. Total loss for the insulated pressure vessel with MLVSI and fueled with $\mathrm{LH}_{2}$ (Vessel 2) is only $1 \mathrm{~kg}$ after 1 month of dormancy. In addition to this, the insulated pressure vessels keep about a third of the original capacity even after reaching thermal equilibrium with the environment. This may be important for avoiding the inconvenience of running out of fuel after a long period of dormancy.

Figure 7 shows cumulative hydrogen losses as a function of the number of days that the vehicle remains idle, assuming the more reasonable case of having the vessel half full $\left(2.5 \mathrm{~kg}\right.$ of $\left.\mathrm{H}_{2}\right)$ at the moment when the vehicle is parked. The figure shows that the low-pressure $\mathrm{LH}_{2}$ storage starts losing fuel after 1 day, compared to 2 days with no losses for a full tank (Figure 6). The low-pressure $\mathrm{LH}_{2}$ tank loses most of its fuel after only 10 days. On the other hand, insulated pressure vessels have substantially improved dormancy characteristics when the vessel is initially half full, because the pressure and temperature of the vessel have to increase considerably before there is a need for venting. Vessels insulated with microspheres start having losses only after 10 days of parking, and MLVSI vessels can spend 40 days of inactivity without losses. These results are very insensitive to the initial state of the fuel.

Figure 8 shows the number of days before fuel loss (before any amount of hydrogen has to be vented from the vessel) as a function of daily driving distance. This may be an important figure of merit, if public perception of fuel venting is very negative. Only fuel losses during operation are considered for this figure. Some of the vessels may lose hydrogen during fueling. These losses are not taken into account in Figure 8. See Figure 9 for an analysis of hydrogen losses during fueling.

Figure 8 shows that, for the insulated pressure vessels, the number of days before fuel losses increases rapidly as the daily driving distance increases. These vessels show a very good performance, even with the microsphere insulation. The number of days before losses for the low-pressure $\mathrm{LH}_{2}$ tank is very insensitive to driving distance, increasing only from 2 days to 3 days when the driving distance increases from zero to $50 \mathrm{~km} /$ day $(100 \mathrm{~km} /$ day for the $34 \mathrm{~km} / \mathrm{l} \mathrm{car}$ ).

Figure 9 shows the results of the analysis of the fueling process of a warm vessel. The figure shows hydrogen losses during fueling and final vessel temperature as a function of the initial vessel temperature. Hydrogen losses shown in the figure result from the initial high temperature of the vessel, and do not include losses due to warm hoses and connecting lines. The process of fueling a vessel is fast enough to be considered adiabatic regardless of the type of insulation, even though limitations in the thermal stress for the vessel may result in a relatively long fueling time (30 minutes). Figure 9 does not include results for the insulated pressure vessel fueled with $\mathrm{LH}_{2}$ (Vessels 2 and 4) because these vessels do not lose any hydrogen, even when the vessel is originally at ambient temperature. This analysis assumes that the vessel is initially empty.

Figure 9 shows that the worst case (starting with a vessel at ambient temperature) results in a loss of $1 \mathrm{~kg}$ of hydrogen for the insulated pressure vessel fueled with $46 \mathrm{~K} \mathrm{CH}_{2}\left(80 \mathrm{~K} \mathrm{CH}_{2}\right.$ initial temperature inside the vessel), and $2.5 \mathrm{~kg}$ for the low-pressure $\mathrm{LH}_{2}$ tank. The final temperature of the insulated pressure vessel is $107 \mathrm{~K}$. The lowpressure $\mathrm{LH}_{2}$ tank remains at $27 \mathrm{~K}$, which is the equilibrium temperature corresponding to a vapor pressure of 0.5 $\mathrm{MPa}$. Hydrogen losses and vessel temperature drop rapidly as the initial vessel temperature is reduced. No losses of hydrogen occur when the initial vessel temperature is less than $100 \mathrm{~K}$ for the insulated pressure vessel, or $150 \mathrm{~K}$ for the low-pressure $\mathrm{LH}_{2}$ tank. The vessel cools down substantially during fueling under all conditions.

As previously established, fueling a vessel with $300 \mathrm{~K} \mathrm{CH}_{2}$ results in a $433 \mathrm{~K} \mathrm{CH}_{2}$ temperature immediately after fueling. The increase in temperature reduces the amount of hydrogen that can be stored in the vessel at a given pressure. To avoid losses in $\mathrm{CH}_{2}$ storage capacity, pressure vessels are often filled to a pressure higher than the design pressure. The pressure then drops to the design pressure as $\mathrm{CH}_{2}$ is extracted from the vessel and the vessel transfers heat to the environment (Pentastar, 1997). However, the increase in temperature may be a significant issue, since the vessel may not be able to withstand the higher pressure for a long period of time. It may be necessary to 
reduce the storage capacity of the vessel, or to fuel the vessel with $\mathrm{CH}_{2}$ at a reduced temperature $(210 \mathrm{~K})$ to avoid the excessive pressure.

Heat transfer to the environment is not significant for insulated pressure vessels, so that the only possibility to reduce the pressure is to extract some $\mathrm{CH}_{2}$ from the vessel. Most drivers do not park their vehicle immediately after fueling, so that fuel extraction may provide the required reduction in pressure. This process has been analyzed, assuming that the vessel is initially empty at $300 \mathrm{~K}$, and $1.6 \mathrm{~kg}$ of $\mathrm{CH}_{2}$ at $300 \mathrm{~K}$ are added during fueling. The results of the analysis are a function of the rate of heat transfer between the $\mathrm{CH}_{2}$ and the vessel walls and the rate of fuel extraction from the vessel. As a detailed analysis of heat transfer inside the vessel is beyond the scope of this work, a worst-case scenario is instead considered: it is assumed that the vessel and the $\mathrm{CH}_{2}$ are always in thermal equilibrium. This is a worst-case scenario because the temperature (and therefore the enthalpy) of the $\mathrm{CH}_{2}$ is lowest in the case of thermal equilibrium, providing the minimum cooling effect for the vessel due to flow work (Equation 1).

The results are shown in Figure 10. This figure shows pressure and temperature for an insulated pressure vessel, as a function of distance driven from the moment in which the vessel is fueled, assuming thermal equilibrium between the vessel and the fuel. The temperature and pressure of the vessel after achieving thermal equilibrium are $328 \mathrm{~K}$ and $27.3 \mathrm{MPa}$. From this point, pressure and temperature drop quickly as the vehicle is driven. The pressure drops below the design pressure (24.8 $\mathrm{MPa}$ ) after driving only $7 \mathrm{~km}$ in a $17 \mathrm{~km} / 1$ gasoline-equivalent vehicle. Therefore, the required reduction in pressure can be achieved if the car is driven for a short distance, even in the worst-case scenario being analyzed. If the vehicle is parked for a long time immediately after fueling, it may be necessary to vent some of the fuel. However, the amount that has to be vented in the worst-case scenario being considered is only $0.1 \mathrm{~kg}$.

\section{CONCLUSIONS}

This paper shows that insulated pressure vessels have good packaging characteristics (low weight and volume), and reduced hydrogen losses during operation, dormancy, and fueling compared with low-pressure $\mathrm{LH}_{2}$ tanks, and therefore appear to be a good alternative for hydrogen storage. Insulated pressure vessels do not lose any hydrogen for daily driving distances of more than $15 \mathrm{~km} /$ day for a $17 \mathrm{~km} / \mathrm{l}, 40 \mathrm{mpg}$ energy equivalent fuel economy. Since almost all cars are driven for longer distances, most cars would never lose any hydrogen. Losses during long periods of parking are also relatively small. Due to their high pressure capacity, these vessels would retain about a third of its full charge even after a very long dormancy, so that the owner would not risk running out of fuel. If the vessel reaches ambient temperature, insulated pressure vessels can be cooled down very effectively by fueling them with $\mathrm{LH}_{2}$ with no losses during fueling. If the vessel at ambient temperature stores $\mathbf{8 0}$ $\mathrm{K} \mathrm{CH}_{2}$, there is a loss of only $1 \mathrm{~kg}$, compared to $2.5 \mathrm{~kg}$ for a low-pressure $\mathrm{LH}_{2}$ tank.

Two insulation materials are analyzed for the insulated pressure vessels: multi-layer vacuum superinsulation (MLVSI) and microsphere insulation. Either of these insulators results in a thermal performance that is superior to the performance of low-pressure $\mathrm{LH}_{2}$ tanks equipped with MLVSI. Therefore, a microsphere insulation may be enough for many applications, potentially allowing a cost reduction for the vessels.

The thermal performance of the insulated pressure vessels has been calculated in this paper. However, many other issues still remain to be analyzed. These include: the infrastructure and cost advantages that may result from the possibility of using hydrogen fuel in either of three states $\left(\mathrm{LH}_{2}, 46 \mathrm{~K} \mathrm{CH}_{2}\right.$, or ambient-temperature $\left.\mathrm{CH}_{2}\right)$; and the manufacturing, cost, safety and refueling issues, which have to be considered in the same form in which they have been studied for low-pressure $\mathrm{LH}_{2}$ tanks (Pehr, 1996b; Hettinger et al., 1996).

\section{ACKNOWLEDGMENTS}

We thank Glenn Rambach and J. Ray Smith for valuable discussions held during the progress of this work.

\section{REFERENCES}

Aceves, S.M., and Smith, J.R., 1996, "Lean-Burn Hydrogen Spark-Ignited Engines: The Mechanical Equivalent to the Fuel Cell," In "Alternative Fuels, Volume 3," Proceedings of the 18th Annual Fall Technical Conference of the ASME Internal Combustion Engine Division, Fairborn, OH, October 1996, pp. 23-31. 
Braess, H.H., and Strobl, W., 1996, "Hydrogen as a Fuel for Road Transport of the Future: Possibilities and Prerequisites," Proceedings of the $11^{\mathrm{t}}$ World Hydrogen Energy Conference, Stuttgart, Germany.

Bunger, U., and Owren, G., 1996, "Development Potentials for Small Mobile Storage Tanks with Vacuum Powder Insulations," Proceedings of the $11^{\text {th }}$ World Hydrogen Energy Conference, Stuttgart, Germany, pp. 10431052.

Hettinger, W. Michel, F., Ott, P., and Theissen, F., 1996, "Refueling Equipment for Liquid Hydrogen Vehicles," Proceedings of the $11^{\mathrm{W}}$ World Hydrogen Energy Conference, Stuttgart, Germany, pp. 1135-1143.

James, B.D., Baum, G.N., Lomax, F.D., Thomas, C.E., Kuhn, I.F., 1996, “Comparison of Onboard Hydrogen Storage for Fuel Cell Vehicles," Directed Technologies Report DE-AC02-94CE50389, prepared for Ford Motor Company.

Mathis, D.A., 1976, "Hydrogen Technology for Energy," Noyes Data Corporation, Park Ridge, NJ.

McCarty, R.D., 1975,"Hydrogen: Its Technology and Implications, Hydrogen Properties, Volume III," CRC Press, Cleveland, Ohio.

Michel, F., Fieseler, H., Meyer, G., and Theissen, F., 1996, "Onboard Equipment for Liquid Hydrogen Vehicles," Proceedings of the $11^{\text {th }}$ World Hydrogen Energy Conference, Stuttgart, Germany, pp. 1063-1077.

Pehr, K., 1996a, "Experimental Examinations on the Worst Case Behavior of $\mathrm{LH}_{2} / \mathrm{LNG}$ Tanks for Passenger Cars," Proceedings of the $11^{\text {th }}$ World Hydrogen Energy Conference, Stuttgart, Germany.

Pehr, K., 1996b, "Aspects of Safety and Acceptance of $\mathrm{LH}_{2}$ Tank Systems in Passenger Cars," International Journal of Hydrogen Energy, Vol. 21, pp. 387-395.

Pentastar Electronics, 1997, "Direct-Hydrogen-Fueled Proton-Exchange-Membrane Fuel Cell System for Transportation Applications, Conceptual Design Report," Report DOE/CE/50390-9, prepared for U.S. Department of Energy, Office of Transportation Technologies, under contract DE-AC02-94CE50390.

Peschka, W., 1998, "Liquid Hydrogen, Fuel of the Future," Springer-Verlag, Vienna, Austria.

Scott, R.B., 1967, “Cryogenic Engineering," D. Van Nostrand Company, Inc. Princeton, NJ.

Smith, J.R., Aceves, S.M., and Van Blarigan, P., 1995, "Series Hybrid Vehicles and Optimized Hydrogen Engine Design," SAE Paper 951955, SAE Transactions, Journal of Fuels and Lubricants, Vol. 104, pp. 816-827.

VanWylen, G.J., and Sonntag, R.E., 1978, "Fundamentals of Classical Thermodynamics," John Wiley and Sons, New York, NY.

Wetzel, F.J., 1996, "Handling of Liquid Hydrogen at Filling Stations," Proceedings of the $11^{\text {th }}$ World Hydrogen Energy Conference, Stuttgart, Germany, pp. 1123-1134. 


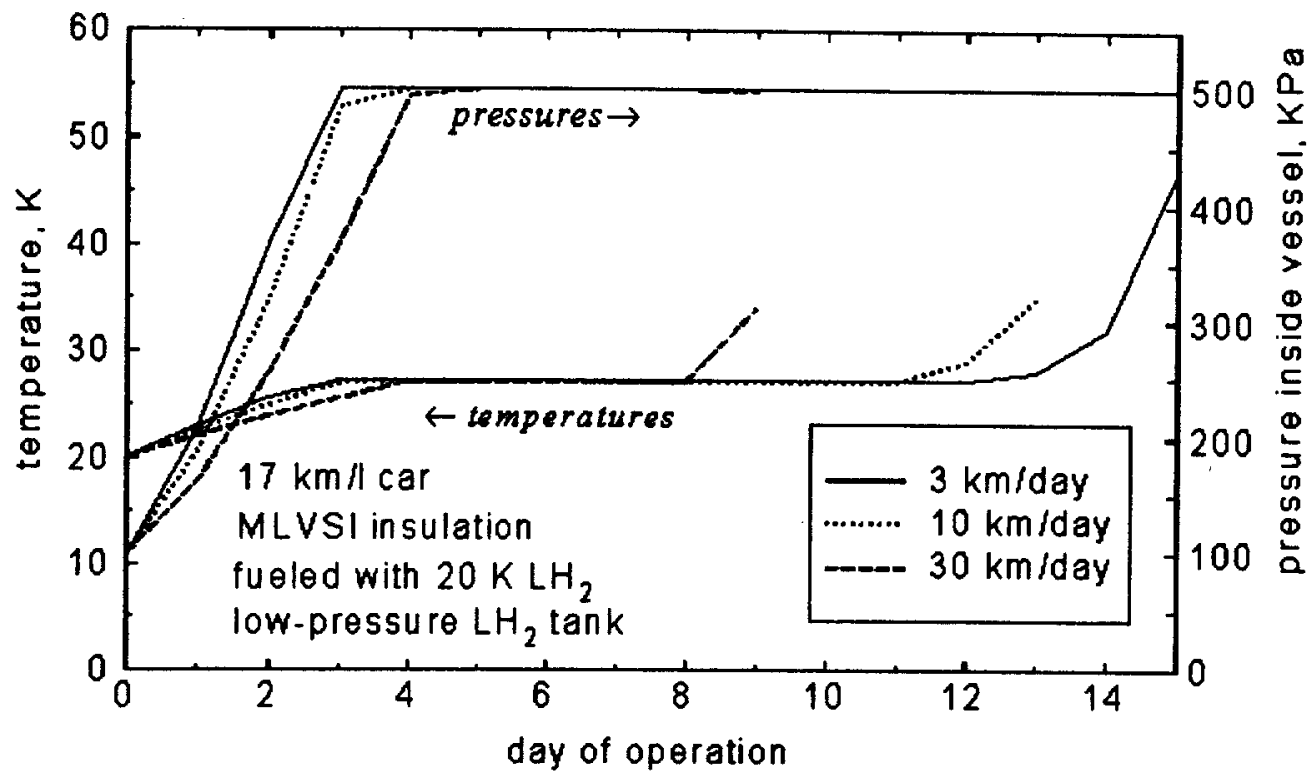

Figure 1. Temperature and pressure inside a low-pressure $\mathrm{LH}_{2}$ tank as a function of the day of operation since the vessel was filled, for three different daily driving distances, for a vehicle with a $17 \mathrm{~km} / \mathrm{liter}(40 \mathrm{mpg})$ fuel economy.

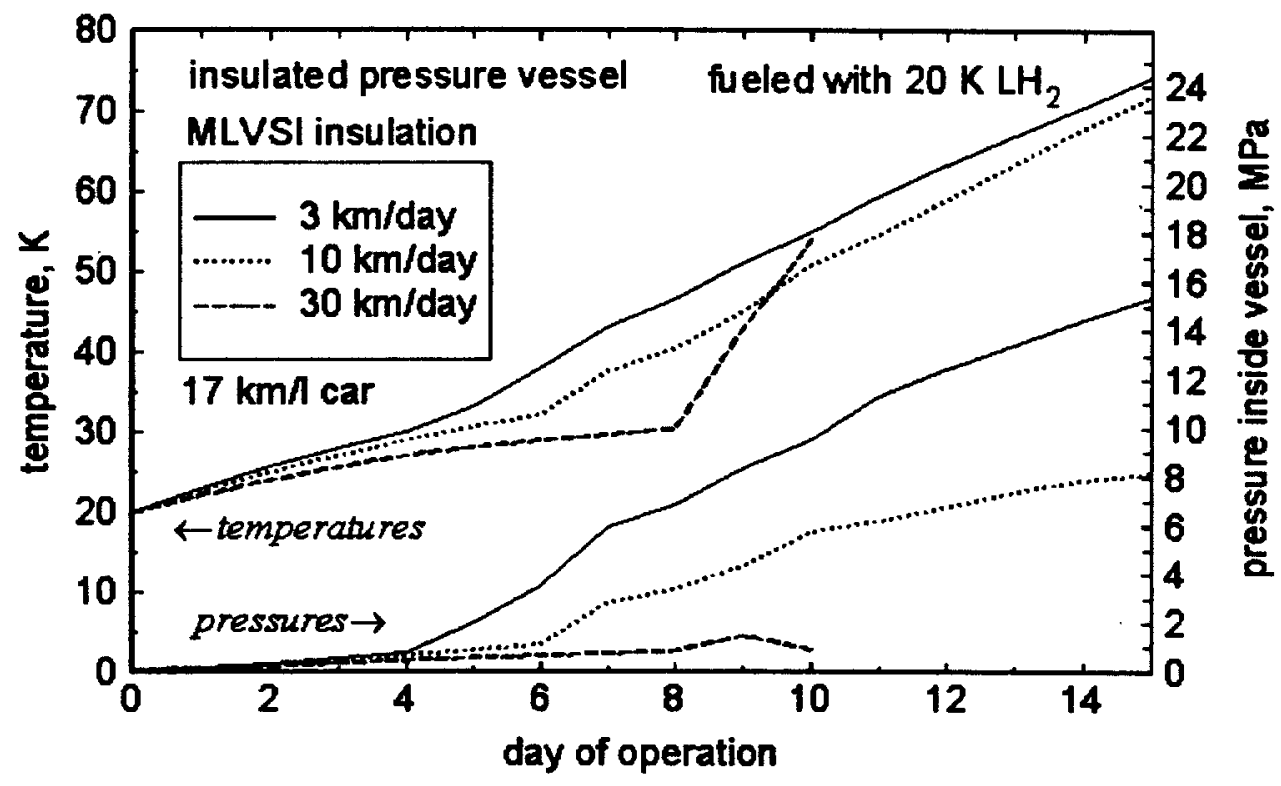

Figure 2. Temperature and pressure Inside an MLVSI Insulated pressure vessel fueled with $20 \mathrm{~K} \mathrm{LH}_{2}$ as a function of the day of operation since the vessel was filled, for three different dally driving distances, for a vehicle with a $17 \mathrm{~km} / \mathrm{liter}(40 \mathrm{mpg})$ fuel economy. 


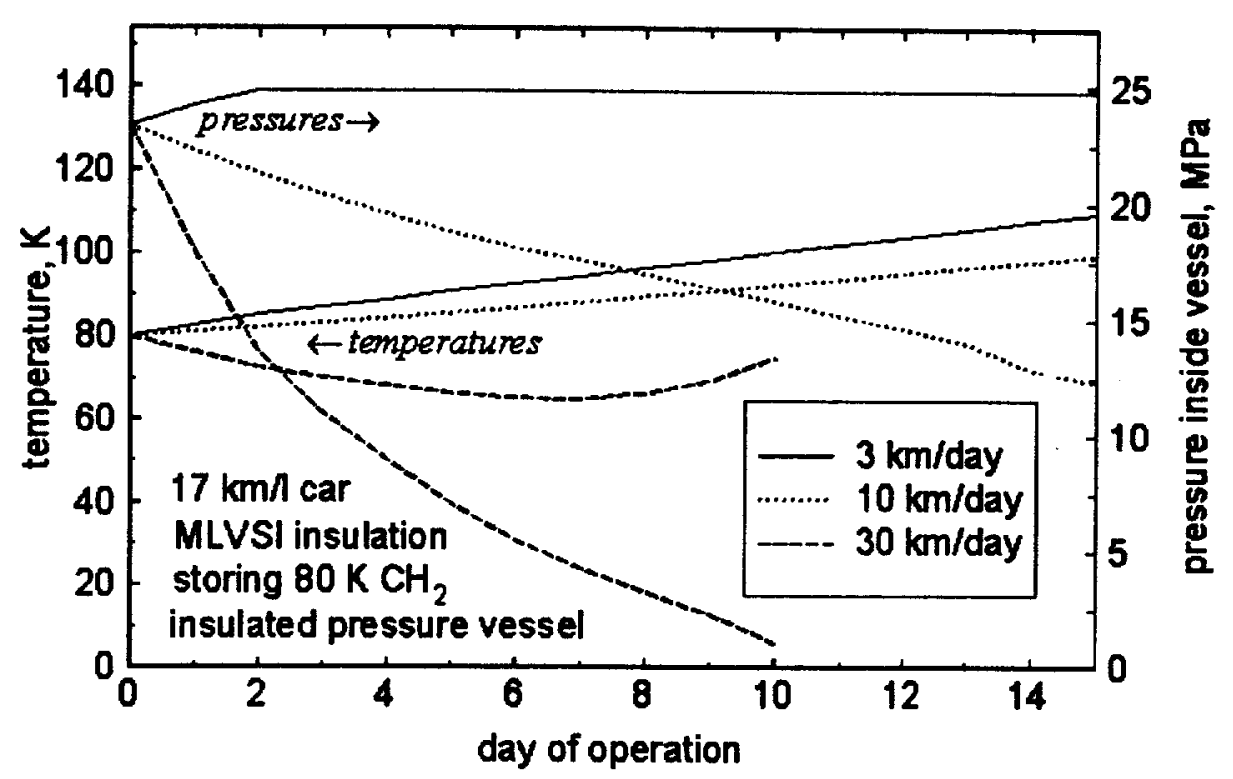

Figure 3. Temperature and pressure inside an MLVSI insulated pressure vessel storing $80 \mathrm{~K} \mathrm{CH}_{2}$ as a function of the day of operation since the vessel was filled, for three different daily driving distances, for a vehicle with a $17 \mathrm{~km} / \mathrm{iter}(40 \mathrm{mpg})$ fuel economy.

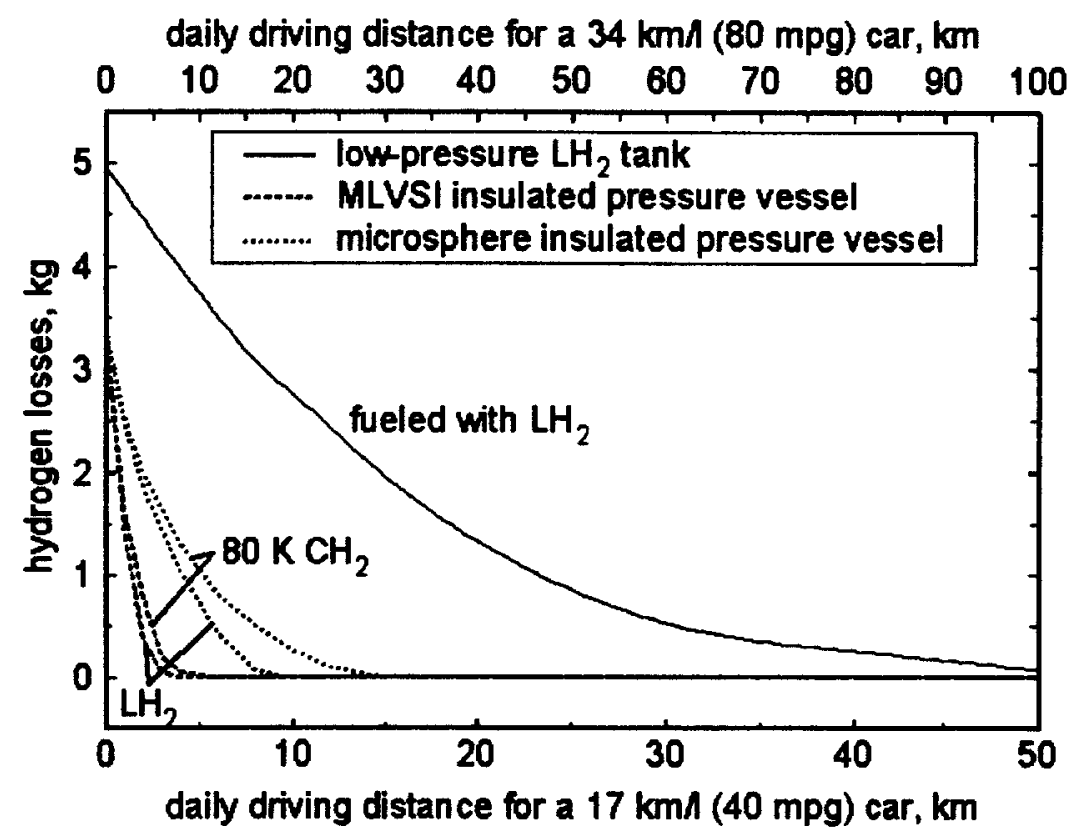

Figure 4. Cumulative hydrogen losses in $\mathrm{kg}$ as a function of daily driving distance, for vehicles with $17 \mathrm{~km} / \mathrm{iter}(40 \mathrm{mpg})$; or $34 \mathrm{~km} / \mathrm{l}(80 \mathrm{mpg})$ fuel economy, for the five vessels being analyzed in this paper. 


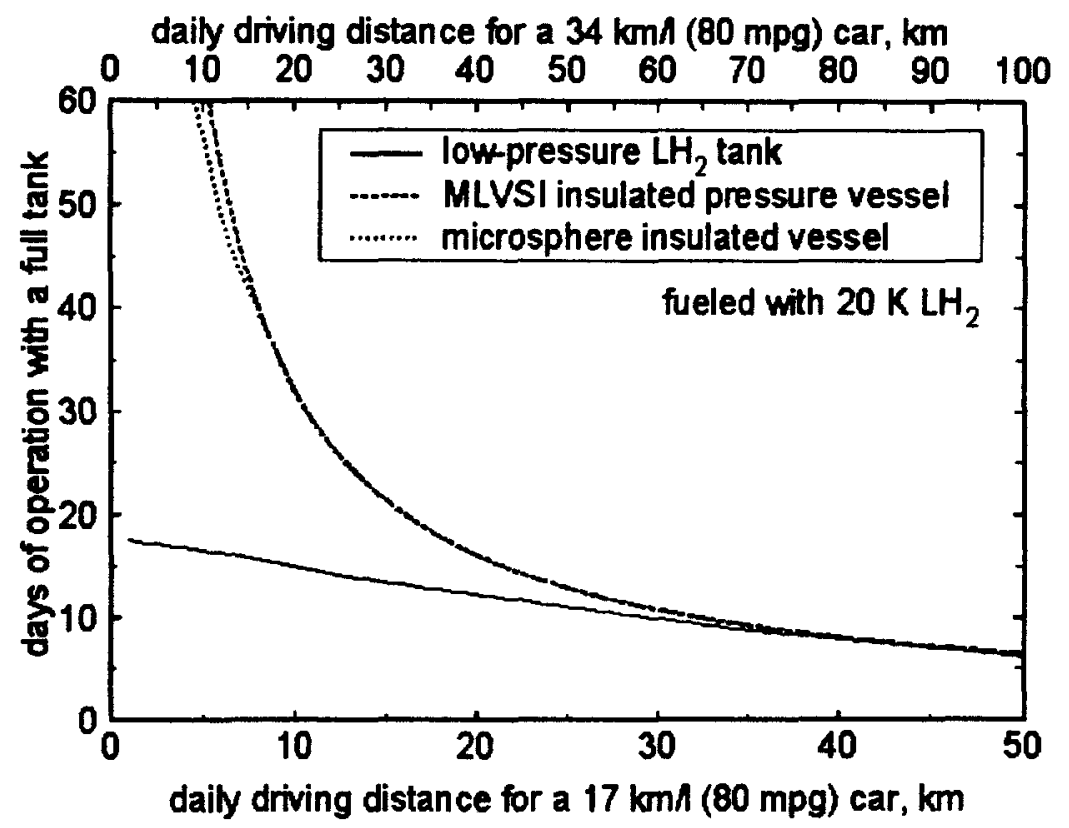

Figure 5. Number of days of vehicle operation with a full vessel of hydrogen (days before running out of fuel), as a function of daily driving distance, for vehicles with 17 $\mathrm{km} /$ iter $(40 \mathrm{mpg})$ or $34 \mathrm{~km} / \mathrm{liter}(80 \mathrm{mpg}$ ) fuel economy, for vessels fueled with $20 \mathrm{~K}$ $\mathrm{LH}_{2}$.

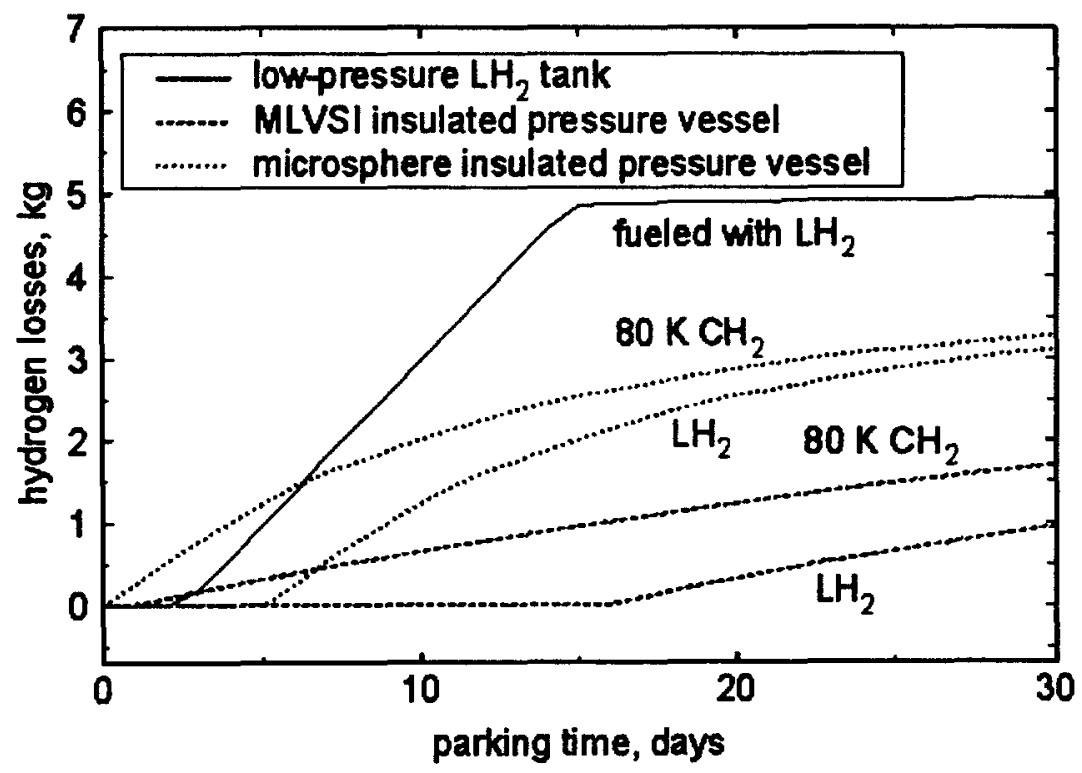

Figure 6. Cumulative hydrogen losses in $\mathrm{kg}$ as a function of the number of days that the vehicle remains idle, for the five vessels being analyzed in this paper, assuming that the vessels are initially full. 


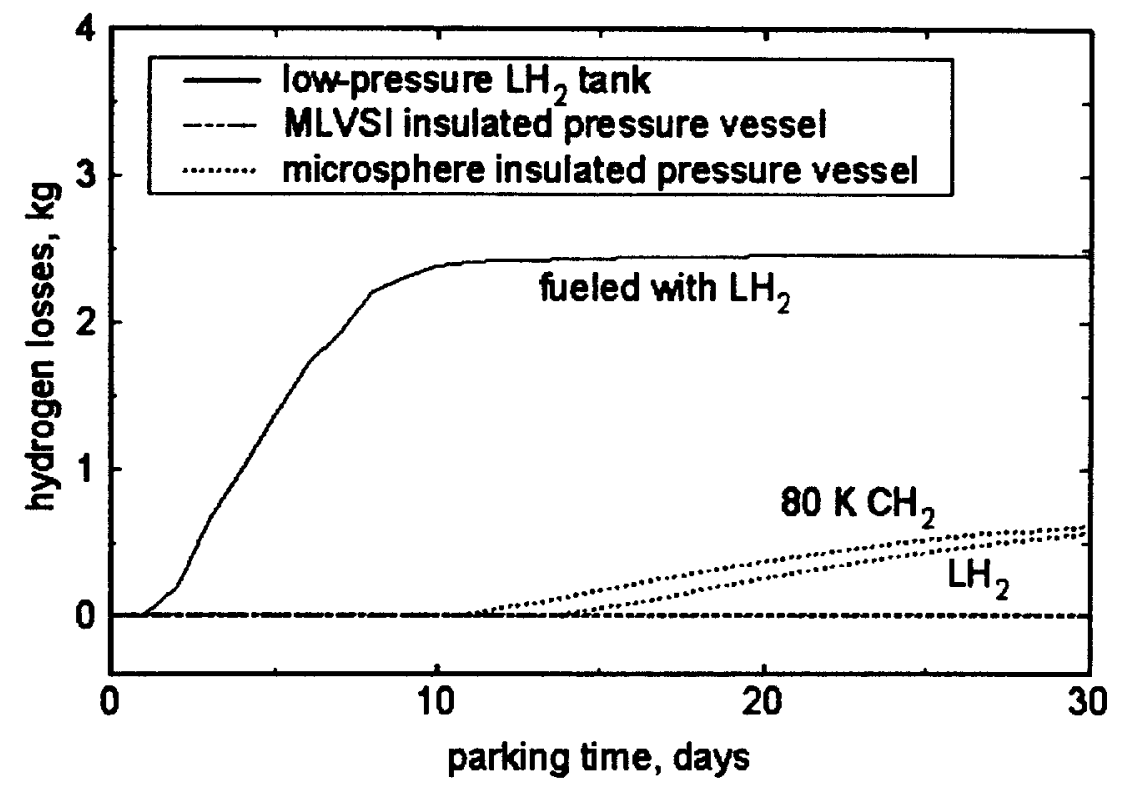

Figure 7. Cumulative hydrogen losses in $\mathrm{kg}$ as a function of the number of days that the vehicle remains idle, for the five vessels being analyzed in this paper, assuming that the vessels are initially half full.

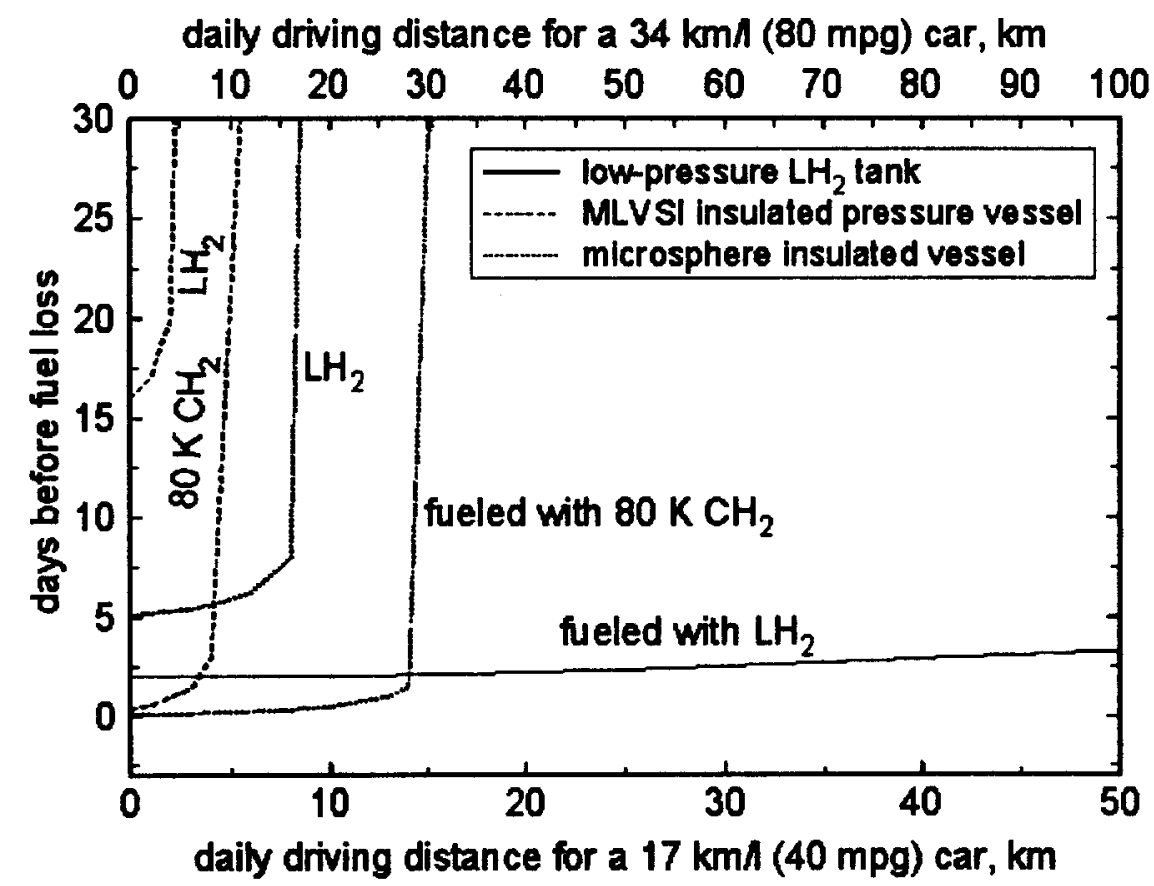

Figure 8. Number of days before fuel loss (before any amount of hydrogen has to be vented from the vessel) as a function of daily driving distance. 


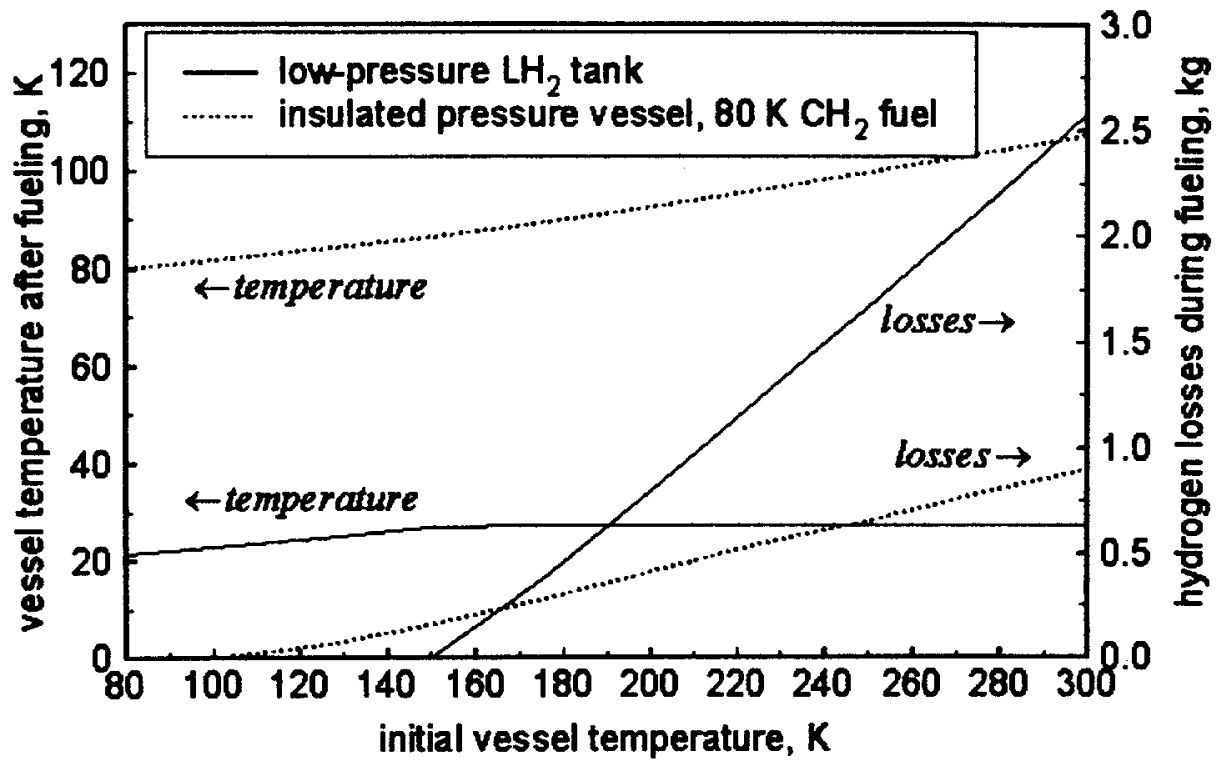

Figure 9. Hydrogen losses during fueling and vessel temperature after fueling as a function of the initial hydrogen vessel temperature.

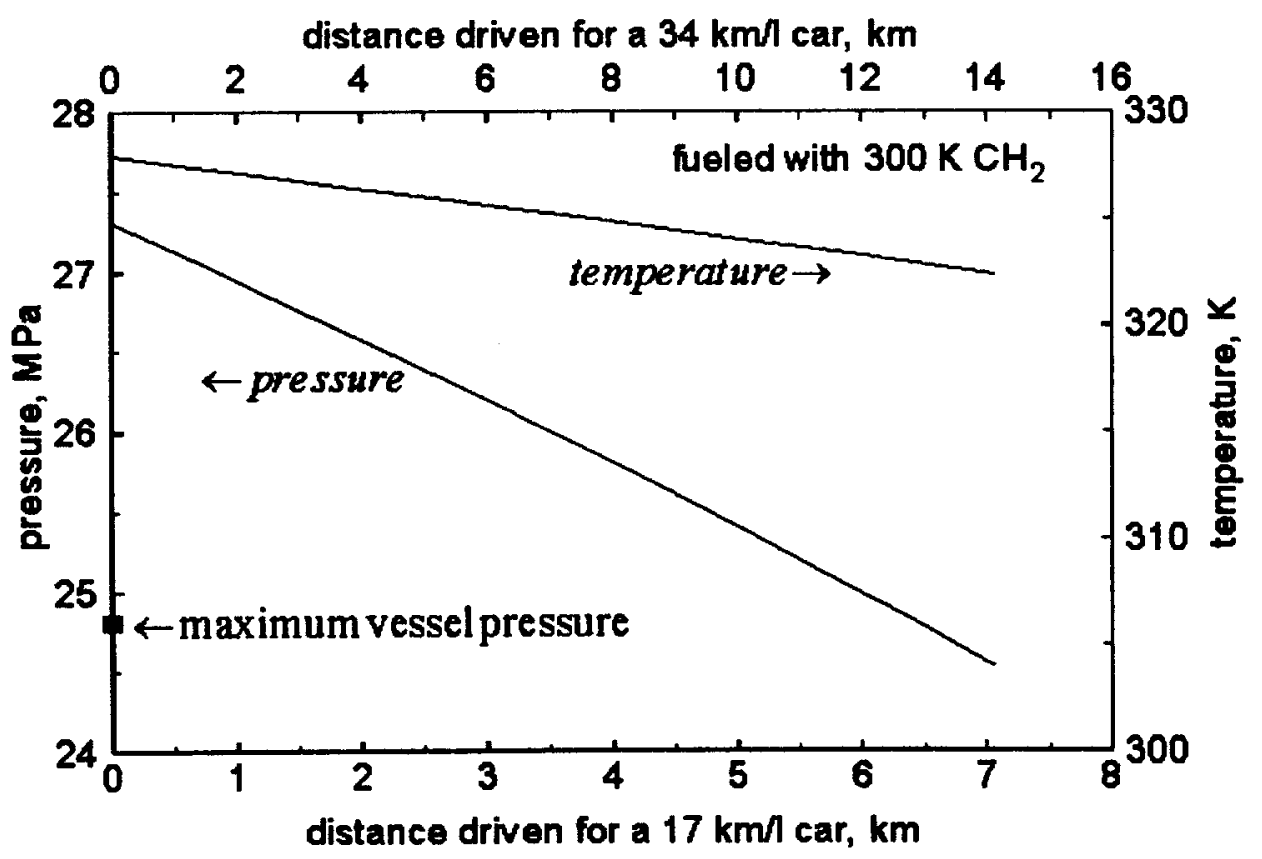

Figure 10. Pressure and temperature for an insulated pressure vessel, as a function of distance driven from the moment in which the vessel is fueled with $300 \mathrm{~K} \mathrm{CH}_{2}$, assuming thermal equilibrium between the vessel and the fuel. 


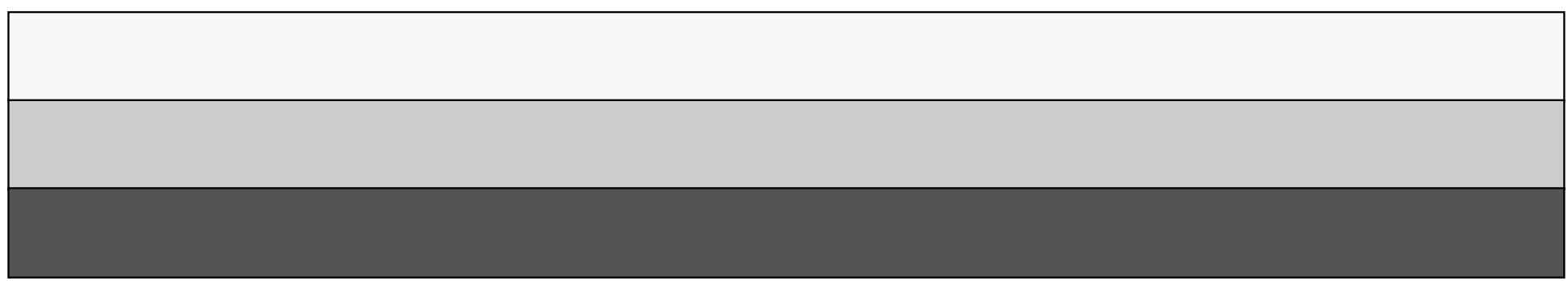

